\title{
GASTOS DO PRÓPRIO BOLSO DAS PESSOAS EM DIÁLISE PERITONEAL: ESTUDO QUALITATIVO ${ }^{1}$
}

\author{
OUT-OF-POCKET EXPENSES OF PEOPLE IN PERITONEAL DIALYSIS: QUALITATIVE \\ STUDY
}

\author{
Juliana Graciela Vestena Zillmer ${ }^{a^{*}}$, Denise Maria Guerreiro Vieira da Silva ${ }^{b^{* *}}$ \\ juzillmer@gmail.com ${ }^{\mathrm{a}}$, denise_guerreiro@hotmail.com ${ }^{\mathrm{b}}$ \\ Universidade Federal de Pelotas*, Universidade Federal de Santa Catarina**
}

\section{RESUMO}

Data de Submissão 18/03/2019

Data de Aceite: 21/10/2019

Introdução: A doença renal crônica representa um problema de saúde pública em nível mundial pelas crescentes taxas de incidência, prevalência e morbimortalidade, com impacto para as famílias e sistemas de saúde. Objetivo: Conhecer os gastos do próprio bolso que as pessoas com doença renal têm para acessar e manter a diálise peritoneal no domicílio. Materiais e Métodos: Trata-se de um estudo qualitativo, sociocultural, com enfoque etnográfico, a partir de uma perspectiva crítico interpretativa, realizado em município no Sul do Brasil. Participaram 20 pessoas em diálise peritoneal ambulatorial contínua; os dados foram obtidos mediante entrevistas abertas e semiestruturadas, e observação participante. Os dados foram analisados mediante análise de conteúdo convencional. Resultados: As pessoas em diálise peritoneal reportaram ter múltiplos gastos do próprio bolso para acessar e manter o tratamento no domicílio. Os gastos mais importantes são para compra de medicamentos, materiais para a diálise, adequação do espaço, consultas médicas, exames e transporte. Conclusões: o sistema de saúde brasileiro, apesar de ter como proposta ser totalmente gratuito e de acesso universal, não consegue garantir esse acesso e manutenção de forma gratuita de todo tratamento para a população com doença renal.

Palavras-chave: Insuficiência renal crônica; terapia de substituição renal; diálise; diálise peritoneal; gastos em saúde; pesquisa qualitativa

\begin{abstract}
Introduction: Chronic kidney disease represents a worldwide public health problem due to rising rates of incidence, prevalence, and morbidity and mortality, impacting families and health systems. Objective: This study aims to know the out-of-pocket expenses that people with kidney disease have to access and maintain peritoneal dialysis at home. Materials and Methods: It is a qualitative and sociocultural study with an ethnographic focus, based on an interpretative critical perspective, carried out in a town located in the South of Brazil. The sample consisted of twenty people on continuous ambulatory peritoneal dialysis. The data were obtained through open and semi-structured interviews and participant observation and were analyzed by conventional content analysis. Results: People on peritoneal dialysis report having multiple out-of-pocket expenses to access and maintain treatment at home. The most important expenses reported are: purchase of medicines, materials for dialysis, appropriateness of space, medical consultations, examinations and transportation. Conclusion: Although the Brazilian Health System proposes to be totally free and accessible to all people, it can not guarantee this access and free maintenance of all treatment for the population with kidney disease.
\end{abstract}

Keywords: Renal insufficiency chronic; renal replacement therapy; dialysis; peritoneal dialysis; health expenditures; qualitative research

${ }^{1}$ Artigo extraído da Tese - Experiências e práticas de pessoas em diálise peritoneal sobre sua condição e atenção à saúde, apresentada ao Programa de Pós-Graduação em Enfermagem da Universidade Federal de Santa Catarina (UFSC), em 2014. 


\section{Introdução}

A doença renal crônica (DRC) representa um problema de saúde pública em nível mundial e no Brasil pelas crescentes taxas de incidência, prevalência e morbimortalidade ${ }^{1,2}$, gera um impacto na vida diária das pessoas, com perda de produtividade e qualidade de vida ${ }^{3,4}$. No país, existem aproximadamente 122.825 pessoas com a DRC dependentes de terapia renal substitutiva, sendo $83 \%$ destas assistidas exclusivamente pelo Sistema Único de Saúde (SUS)².

O Brasil, a partir da Reforma Sanitária de 1988, instituiu que todos os cidadãos têm cobertura universal, gratuita e com equidade mediante o SUS. Diante disso, as pessoas com DRC têm acesso ao tratamento conservador assim como às terapias de substituição renal hemodiálise (HD), diálise peritoneal (DP), e ao transplante ${ }^{5}$, sendo o SUS a principal fonte pagadora ${ }^{2}$. Ao ingressar em um desses tratamentos, elas também terão acesso aos medicamentos; consultas médicas e exames; internação hospitalar; e transporte para continuidade da assistência ${ }^{5}$. Entretanto, temse documentado que no Brasil, assim como em outros países com sistemas universais e gratuitos de saúde ${ }^{6}$, um número cada vez maior de pessoas está gastando do próprio bolso para com a assistência à saúde ${ }^{7,8}$.

O Censo Brasileiro de Diálise demonstrou um aumento do número de pessoas em tratamento no país na última década, porém os custos associados ao tratamento não são abordados nesta análise. Das pessoas em diálise, cerca de 10.000 estão em $\mathrm{DP}^{2}$, a qual se trata de uma terapia renal em expansão, e como importante estratégia para melhorar o acesso ao tratamento da DRC, além de reduzir custos para os sistemas de saúde devido à que sua infraestrutura ser mais simples que a de hemodiálise ${ }^{1}$.

Alguns estudos têm se concentrado em comparar os custos entre diversos tipos de tratamento para a DRC, sendo eles, hemodiálise, diálise peritoneal e transplante ${ }^{9,10}$. Estudo analisou o impacto financeiro no Sistema Único de Saúde e na Saúde Suplementar do tratamento por hemodiálise e diálise peritoneal, versus transplante renal, apontando que no primeiro ano o custo médio para receptores de transplante foi maior do que o de pacientes mantidos em hemodiálise, decrescendo significativamente no segundo ano, enquanto que o tratamento por hemodiálise permaneceu inalterado9. Tais achados corroboram com resultados de outro estudo mostrando que o transplante renal, embora mais caro no primeiro ano, torna-se mais barato a partir do segundo e, portanto, apresenta melhor custo-benefício quando comparado às diálises ${ }^{10}$.

Entretanto, são poucos os estudos qualitativos interessados em conhecer os gastos do próprio bolso das pessoas com a doença para acessar e manter o tratamento ${ }^{4,7}$. Estudo desenvolvido no Brasil com pessoas com DRC e seus familiares no acesso à hemodiálise identificou que as pessoas com uma situação econômica mais elevada optavam por pagar as consultas com especialistas, realizar exames e comprar os medicamentos necessários de forma mais rápida do que pelo SUS ${ }^{(7)}$.

Outro estudo desenvolvido no México examinou as dificuldades económicas e seu efeito em pessoas que realizaram transplante renal sem proteção social, os resultados apontaram que o transplante empobreceu as pessoas doentes sem proteção social a saúde, sinalizando a urgência para implementação de um sistema de saúde para esta população ${ }^{4}$. Outro estudo identificou que minorias étnicas raciais e pessoas de nível socioeconômico mais baixo têm menor probabilidade de receber transplantes reforçando a desigualdade no acesso ao tratamento ${ }^{11}$.

$\mathrm{Na}$ atualidade, o Brasil é considerado, um dos países da América Latina com crescente gasto do próprio bolso ${ }^{6}$, principalmente com medicamentos, planos privados, e tratamento odontológico $^{12}$. Neste contexto, poucos estudos têm explorado os gastos diretos das pessoas com doença renal no Brasil 7 . O tema é de interesse no País pela crescente expansão da DRC, incluindo o aumento do ingresso nas terapias renais substitutivas, que são responsáveis pela elevação dos gastos em saúde².

A DRC é tratada no sistema de alta complexidade do SUS, afora incluir outros níveis de atenção, de forma a atender as necessidades globais das pessoas com a doença ${ }^{5}$ Além disto, há disparidades econômicas e regionais, como por exemplo, o acesso diferenciado ao 
transplante, expresso na existência de maior taxa de transplantes nas regiões do país com maiores níveis de renda ${ }^{13,14}$. A partir do exposto, o presente estudo teve como objetivo conhecer os gastos do próprio bolso das pessoas com doença renal para acessar e manter o tratamento de diálise peritoneal ambulatorial contínua (CAPD) no domicílio em um município do Sul do Brasil.

\section{Método}

Trata-se de um estudo qualitativo, sociocultural com enfoque etnográfico, a partir de uma perspectiva crítico-interpretativa ${ }^{15}$, realizado em um serviço de nefrologia de um município do Rio Grande do Sul, Brasil. Tal serviço era referência em diálise peritoneal e contava com o maior número de pessoas em tratamento na região. A coleta de dados foi desenvolvida entre abril de 2013 e junho de 2014. A pesquisa foi desenvolvida pela primeira autora, enfermeira, pesquisadora que possuía o título de Mestre e encontrava-se realizando o doutorado, devidamente capacitada e com experiência nessa área do conhecimento.

Os critérios para seleção dos participantes limitaram-se a: homens e mulheres cadastrados em diálise peritoneal ambulatorial contínua havia mais de seis meses; que residissem em áreas urbanas e rurais, e não apresentassem dificuldade de comunicação, avaliado subjetivamente pela investigadora. Participaram do estudo 20 pessoas em CAPD mediante amostragem intencional e teórica a partir da agenda de consulta dos pacientes cadastrados no programa de diálise; sendo o tamanho da amostra baseado na saturação dos depoimentos contidos nas entrevistas.

As técnicas de coleta de dados incluíram a observação participante, entrevistas aberta e semiestruturada, e consulta aos prontuários. Foram elaborados guias para ambos os tipos de técnicas, observação e entrevistas, em consonância com os objetivos do estudo. A observação participante ocorreu no serviço de nefrologia, na unidade de internação hospitalar e no domicílio das pessoas em CAPD. Tal técnica teve como objetivo descrever o contexto, as atividades desenvolvidas pelas pessoas em diálise, assim como as formas como se estabeleciam as relações com familiares, e com o sistema de saúde, incluindo os profissionais que nele atuavam. A partir das observações foram elaboradas notas de campo fornecendo informações contextuais para complementar a análise das entrevistas, assim como documentar e descrever o trabalho de campo.

As entrevistas foram desenvolvidas individualmente, em horários previamente definidos com os participantes, com uma duração de 60 a 180 minutos. A entrevista aberta, primeira a ser realizada, foi norteada pela questão "Podes me contar desde que começou a doença dos rins?”. Nas entrevistas subsequentes foram aprofundados temas que surgiram no decorrer do trabalho de campo e também a partir da análise na entrevista anterior. Os participantes foram, na maioria, entrevistados em seus domicílios, com exceção de quatro pessoas, sendo estas entrevistadas em uma sala reservada do serviço de nefrologia, conforme escolha do participante. Oito foram entrevistados duas vezes, sendo a segunda uma entrevista semiestruturada. Os demais, não foi possível entrevistá-los pela segunda vez, devido à saída da CAPD por óbito ou mudança para a hemodiálise.

As vinte entrevistas foram gravadas e transcritas na íntegra por dois transcritores capacitados, sendo posteriormente revisadas pela pesquisadora, com a escuta dos áudios gravados e uma leitura exaustiva das mesmas. Os prontuários foram consultados com o objetivo de identificar informações sociodemográficas, clínicas e do local onde residiam visando conhecer a condição de saúde para complementar os demais dados coletados. O tamanho da amostra e finalização da coleta de dados foi determinado pelo critério de saturação de informações, na medida em que a informação coletada se repetia.

Para organização e gerenciamento das informações oriundas da observação participante e das vinte entrevistas foi utilizado o Programa Ethnograph V6. O conjunto de dados oriundos da observação participante e entrevistas, respectivamente notas de campo e transcrições, foram analisados mediante análise de conteúdo do tipo convencional ${ }^{(16)}$ a partir do objetivo proposto. Logo, a análise consistiu na leitura, por parte da primeira autora, de todos os dados a fim de atingir a imersão e obter uma compreensão do todo. 
Em seguida, procedeu à leitura linha a linha, até geração de códigos. Em seguida, os códigos foram comparados e fragmentos de texto selecionados para identificação dos temas, que posteriormente deram origem as categorias ${ }^{16}$, sendo estas definidas pela pesquisadora principal. Durante este processo, foram identificados vários temas relacionados às dificuldades quanto à atenção à saúde das pessoas em CAPD, porém o tema sobre os gastos próprios das pessoas em acessar e manter o tratamento foi um dos mais frequentes e de maior relevância para os participantes.

Para manter o rigor no estudo, foram utilizadas as seguintes estratégias: mediante a utilização de um sistema comparativo das técnicas de coleta de dados (observação participante, entrevista aberta e semiestruturada, e análise de prontuário), desenvolvidas em um período prolongado de tempo, nos contextos onde as pessoas em CAPD experienciaram o fenômeno. A qualidade dos dados obtidos também foi garantida mediante a reflexibilidade, ou seja, a constante análise e reflexão, capaz de reconhecer, durante a interação com os participantes da pesquisa, pontos que necessitavam ser esclarecidos e aprofundados, atingindo o objetivo do estudo.

A pesquisadora principal, primeira autora, contou com bolsa da Coordenação de Aperfeiçoamento de Pessoal de Nível Superior; E aprovada pelo Comitê de Ética em Pesquisa da Universidade Federal de Santa Catarina sob o Parecer de número 538.882. Todos os preceitos éticos da Resolução 466/12 foram seguidos ${ }^{17}$. Todas as pessoas participantes assinaram o Termo de Consentimento Livre e Esclarecido (TCLE). Para garantir o anonimato dos participantes utilizaram-se pseudônimos.

\section{Resultados}

A partir da análise dos dados, foi possível identificar cinco temáticas relacionadas aos gastos do próprio bolso que as pessoas em diálise peritoneal ambulatorial contínua têm para acessar e manter o tratamento no domicílio, sendo estas apresentadas a seguir.

\section{Quando os medicamentos não estão sempre disponíveis}

As pessoas com DRC em CAPD utilizavam regularmente inúmeros medicamentos, sendo comum a associação concomitante de múltiplos fármacos de uso contínuo. Sendo eles, orais e ou injetáveis, como: vitaminas, eritropoietina, hidróxido de ferro, carbonato de cálcio, complexo $\mathrm{B}$, e furosemida; além de outros quando somados àqueles prescritos para outros comorbidades, tais como: anti-hipertensivos, hipoglicemiantes, ansiolíticos, e ou antidepressivos, visto que todos os participantes tinham outras doenças crônicas que também exigiam a utilização de fármacos.

De acordo com os participantes deparavam-se, com frequência, com a ausência destes medicamentos nas unidades básicas de saúde (UBS) e ou secretaria estadual de saúde. Em decorrência da tentativa fracassada de obter o medicamento no SUS, os participantes compravam os medicamentos para seguir o tratamento prescrito, como descreveu Sueli em seu relato.

Às vezes compro remédios porque não tem nos postinhos de saúde. Tenho minha ficha nos dois postos [Posto X], porque às vezes não tem aqui, vou lá no outro. [Posto Y] está muito precário de remédio, o remédio está difícil de conseguir. (Sueli)

Há outros medicamentos que as pessoas em CAPD necessitavam, porém alguns faziam parte do componente da assistência farmacêutica disponibilizados gratuitamente pelo SUS, porém prescritos pelo médico como parte do tratamento, como alguns antibióticos ansiolíticos e antidepressivos. Esta situação pode ser evidenciada no relato de Joana, quando faz referência a um antibiótico de uso contínuo para proteger o orifício do cateter inserido no abdômen contra infecções.

[...] o colírio [gentamicina] tem que comprar, custa vinte e poucos pilas [reais], um vidrinho, coisinha de nada, vinte e uns quebrados, é caro, é antibiótico. Preciso usar [uso diário em cada troca de curativo]. (Joana)

Para conseguir os medicamentos, os participantes tiveram que peregrinar de um serviço ao outro da rede, na tentativa de obtê-lo gratuitamente. Essa peregrinação pelos serviços 
gerava mais gastos com os deslocamentos, gastos estes do próprio bolso. Quando não encontravam nas UBS, compravam os medicamentos na farmácia popular, programa do governo que oferece um preço menor quando comparado ao de outras farmácias tradicionais. Segundo eles, buscavam essa farmácia como uma estratégia de conseguir pagar menos pelo medicamento por meio de descontos, que ajudavam a diminuir os gastos totais para assegurar a continuidade do tratamento.

\section{Quando o kit de diálise não é suficiente}

As pessoas com DRC em CAPD recebem mensalmente, em seus domicílios, um kit de diálise para o tratamento. O mesmo está constituído por bolsas de infusão e drenagem, protetores de catéter, clamps plásticos, máscaras faciais descartáveis e fita adesiva. Tal kit é solicitado no serviço de nefrologia onde estão cadastradas e é entregue no domicílio. Entretanto, para realizar a troca diária das bolsas de diálise, estas pessoas referem necessitarem de outros materiais que não estavam inclusos no kit disponibilizado, tais como gazes, álcool 70\%, e álcool iodado.

Segundo os participantes, tratava-se de materiais indispensáveis e de uso contínuo, utilizados para os cuidados com o cateter, no curativo, na limpeza dos móveis e utensílios, e na troca das bolsas de diálise. Desse modo, na perspectiva dos participantes, o que é disponibilizado no kit e útil, porém não suficiente para as trocas de diálise diárias. Tais achados podem ser exemplificado no seguinte segmento.

Vem num caminhão [...] eles dão a bolsa, dão umas tampinhas, dão clamplisinho, aqueles que prende a bolsa, dão máscaras, vem quase tudo. A única coisa que não ganho é gaze e álcool, isso tem que comprar [...]. Gasto mais ou menos uns 80 reais, e álcool é cinco reais cada litro, gasto mais ou menos cinco litros por mês [...]. (Júlia)

As unidades básicas de saúde deveriam, segundo as orientações dos profissionais do serviço de nefrologia aos participantes, disponibilizar os materiais como gazes, álcool 70\%, e álcool iodado às pessoas em diálise como parte da atenção à saúde. Entretanto, as pessoas indicaram que quando buscavam estes materiais nas unidades não os conseguiam por duas razões: primeiro, porque não encontravam os materiais, e segundo, quando havia, só era oferecida uma quantidade limitada, não sendo suficiente para atender suas necessidades diárias. Tais situações geravam despesas mensais, que, quando associadas a outras despesas do tratamento, geravam um gasto significativo, como descreve Paula.

[...] comprei todo material, gastei bastante, bah! O álcool iodado aqui [posto de saúde] eles não dão, e é quinze reais o vidro do álcool iodado, e o álcool 70 também é caro. Tudo isso compro todo o mês, tenho essa manutenção. O que vem para mim é os canos, essas coisas [diálise]. Procuro pegar gaze para fazer o curativo no posto, mas às vezes não tem. [...] tudo é comprando... não é fácil [...] (Paula).

A falta dos materiais nas unidades básicas de saúde leva-os a conflitos constantes com o pessoal das unidades, que parecem não compreender as demandas que a doença e a DP geram. No relato de André está claro tal problemática:

Sim, tem que comprar, porque aqui no hospital eles dão uma folha que é para o posto de saúde te fornecer, só que vou no posto e nunca tem, nunca tem. Para conseguir umas gazes é uma briga, tu vai lá, eles te dão cinco, seis pacotinhos de gaze, cinco, seis gaze tu gasta em cada seção que vai fazer, então, cada seção que tu vai fazer, tu é obrigado a ir lá, pedir, pedir e nem sempre tem [...] (André).

Alguns participantes reivindicaram seu direito de receber gratuitamente esses materiais, porém, os profissionais das unidades básicas de saúde, indicavam que eles poderiam comprar por serem de baixo custo. Entretanto, a situação financeira dessas pessoas era precária, pois devido à doença e ao regime de diálise, a maioria, precisou abandonar o trabalho, e passar a viver de uma aposentadoria que representava menos do que recebiam anteriormente, além de terem esses novos gastos. No relato de Mário reconhece que receber esses materiais é um direito que têm,

[...] tem uma menina que trabalha (na farmácia) que falou com minha irmã e minha mãe: "o álcool é baratinho, ele pode comprar". A mãe disse assim: "Tá, mas é um direito dele. A gente sabe que o álcool é barato, mas lá no hospital disseram que pode pegar nos postos de saúde". (Mário) 


\section{Modificando o espaço no domicílio para a diálise}

Ao receberem o diagnóstico de doença renal, e serem encaminhados para DP, os participantes foram orientados a preparar e adaptar a casa para realizar o tratamento, acomodar os móveis e equipamentos necessários. Alguns adaptaram o quarto ou a sala, e outros construíram uma "peça" específica, porém ambos geraram gastos. Os gastos mencionados pelos participantes foram com a compra de materiais de construção, como piso, azulejos, e tintas, além da mão de obra para construí-la.

O preparo desse espaço não é financiado pelo SUS, restando às pessoas pagarem pela adequação para receberem a DP em casa. Trata-se de gastos pontuais que ocorreram ao iniciarem o tratamento, mas que, na perspectiva das pessoas, foram elevados, comprometendo a renda familiar, principalmente nas famílias em que havia apenas um provedor do sustento.

[...] a gente gastou uns quantos troco. Gastamos uns 1000 pila [reais], mais ou menos, porque bota piso, pinta. A gente pintou com aquela tinta antimofo, apesar de que tinta não é barato, não é fácil [...] no quarto tem que ter água instaladinha, até pia ali instaladinha [...]. (Júlia)

A preparação do espaço para DP também requer a aquisição de diversos móveis e equipamentos. Os participantes do estudo necessitaram comprar uma pia para lavagem das mãos; uma mesa para dispor as bolsas; armários (balcão, estante) para guardar as gazes, álcool, medicamentos, kit de diálise; um suporte para a bolsa; uma cadeira; além de micro-ondas para aquecer as bolsas. Evidenciamos no relato de Mário tal situação.

[...] tudo isso, pia, cômoda, e mesa, a gente teve que comprar [...]. Faz uns seis meses atrás que recebi um dinheiro, então a gente já sabia que iniciando, fazendo essas bolsas, que eu ia ter que construir uma peça, que ia ser tudo com azulejo, cômoda assim, cadeira, a mesinha aquela de vidro, tivemos que comprar, pôr pia, isso aí tudo a gente colocou, tudo a gente comprou, sabe [...] é gasto. (Mário)

\section{Agilizando as consultas e exames}

As consultas médicas e exames são proporcionados pelo SUS de forma gratuita, incluindo a atenção básica, ambulatorial, e especializada. Entretanto, em dois momentos precisaram gastar com consultas médicas e com realização de exames: no momento do diagnóstico da doença renal, e, no atendimento com especialistas. Alguns participantes conseguiram marcar consulta e serem atendidos em UBS, porém essas consultas não foram resolutivas. Assim, não obtendo melhora, buscaram por um atendimento particular, pagando do próprio bolso, tanto para acessar o clínico geral como os especialistas. No relato de Lívia, fica evidente tal situação,

Quando fiz o exame na unidade básica de saúde, a doutora disse que eu não tinha nada, mas eu continuei com os mesmos sintomas, $e$ piorando. Aí fui no médico particular, levei os exames que tinha feito. Ela disse que eu já estava com o rim funcionando bem pouco, ela me indicou o nefrologista, por isso escolhi o doutor [...] para o tratamento. Aí paguei a consulta com a médica, com o nefrologista, e depois que ele viu que tinha que fazer diálise, entrei pelo SUS, automaticamente. (Lívia)

O tempo de espera, da atenção básica à especializada, ou seja, entre a consulta e exames realizados e até conseguir uma nova consulta com especialista, pode resultar em um longo período de espera por atendimento no SUS. De acordo com os participantes, os resultados dos exames demoravam a chegar a suas mãos, e para avaliação médica, estando, portanto, na maioria das vezes, desatualizados. Quando desatualizados, se viam obrigadas a conseguir uma nova consulta, para obter um novo pedido de exame para realizálos, o que as levava a peregrinar pelos serviços de saúde. Tal situação foi mencionada por André da seguinte forma,

[...] o doutor do postinho disse: "Vou te encaminhar para um nefrologista." Foi quando em 2006 fui consultar com ele, -o doutor nefrologista-, e comecei a fazer uma avaliação, só que comecei a fazer pelo SUS. O que é que acontece? Ele me pediu um exame, como ele é um doutor muito requisitado, é difícil tu conseguir ficha para ele até fazer o exame. Fiz o exame, até conseguir ficha para ele de novo, 
quando chegava nele os exames já não tinham validade, ele me pedia outro. No início de 2007, fiz uma consulta, mas paguei uma consulta particular no consultório. Lá no consultório dele... ele me pediu mais dois exames, uma era cintilografia. Aí foi diagnosticado que meu rim tinha perdido a função. Ele me explicou direitinho como é que tinha que ser, só que a cirurgia tinha que ser pelo SUS, e então tinha que esperar. Fui esperando, só que o problema foi agravando. Em outubro não deu mais, parei na emergência. (André)

Nesse processo de busca por uma definição de sua condição de saúde, apareciam outros gastos, como realização de exames e deslocamentos. O tratamento odontológico era outra necessidade decorrente da doença e da DP que gerava gastos, por ser de difícil acesso na atenção básica. Quatro participantes pagavam mensalmente por um plano privado de saúde, pois perceberam que estavam gastando mais do que o esperado, pagando particular, por não obterem uma resposta para o seu problema no sistema público de saúde. Adquiriram planos por diversos motivos, mas especialmente pela dificuldade de acesso às consultas e realização de exames. Sueli descreve em seu relato tal situação.

[...] fui nele [cardiologista] e ele me indicou uma doutora, lá da Universidade $\mathrm{X}$, mas a doutora estava de férias, e não consegui consultar. Cheguei lá na Universidade, no ambulatório ali, mas não consegui ninguém para me atender [...]. Aí fui à outra doutora de nefrologia lá no consultório, aí fui particular, paguei a consulta. [...] Aí ela olhou e disse: "a senhora faça esse exame.". Aí fiz ali na Clínica Y, tudo pago [...] eu disse para o meu marido: "Rui, te associa na associação [convênio] dos aposentados, nós estamos gastando e gastando e não está adiantando nada”. [...] faz no teu nome que vou ser a tua dependente. [...] Aí foi quando marcamos a consulta com a doutora [...]. (Sueli)

\section{Deslocando-se para os serviços de saúde}

O deslocamento do domicílio ao serviço de nefrologia e demais serviços de saúde, unidades básicas de saúde e pronto atendimento, também representavam parte dos gastos das pessoas em DP. Uma vez ao mês necessitavam realizar consultas médicas, e exames para acompanhamento no serviço de diálise, e, quando iam, estavam acompanhadas por um familiar. Além disso, quando em situações agudas, por complicações da doença e da diálise, necessitavam ir até outros serviços de saúde gerando gastos inesperados.

Gastos gerados pelo deslocamento foram mencionados com frequência, especialmente, entre aquelas pessoas que viviam na área rural, que associados a outras despesas que envolviam direta e indiretamente o tratamento, eram elevados. Alguns participantes mencionaram que gastavam com transporte público dentro da cidade, outros com o uso do táxi para se deslocarem até o serviço de diálise, devido à debilidade que se encontravam. Entretanto, houve situações inesperadas, em que utilizaram transporte particular. Pagavam pelo transporte do interior à cidade, e também dentro da cidade. Tal situação é evidenciada no relato de Maria,

[...] pego o ônibus ali de São Lourenço vou até o Centro, lá pego táxi, pago oito reais da Praça para ir lá embaixo [serviço de nefrologia], e volto de ônibus [...] Então a despesa assim, cada vez que vamos [marido a acompanha], dá mais ou menos quarenta reais. Todas as vezes que tenho que ir assim, com táxi junto, tudo dá uns quarenta reais, mais a gasolina que gasta, mais o que preciso, tudo, essa é a despesa que tem. [...] agora na oficina, o vizinho teve que levar no Pronto-Socorro e tive que pagar cem reais. Lá não custa nada, é bem atendido e tudo, mas a viagem custa. (Maria)

\section{Discussão}

Os resultados do presente estudo evidenciaram que as pessoas com DRC em CAPD tiveram múltiplos gastos para acessar e manter o tratamento no domicílio, entre eles estão: gastos com materiais de uso diário, consultas médicas e exames, medicamentos, preparo do domicílio e deslocamento para os serviços de saúde. Frente tal achado questiona-se a gratuidade pelo SUS no Brasil levando as pessoas a ter acesso desigual a bens e serviços de saúde, sendo esta uma das formas pelas quais a desigualdade é manifestada.

A dimensão que mais preocupava os participantes quanto aos crescentes gastos com o 
tratamento era dos materiais de uso diário, como gaze e álcool, necessários para o curativo diário, higiene do kit de diálise, dispositivos, e moveis, com a finalidade de evitar infecções. As pessoas em CAPD reconheceram a importância de receber o kit gratuito pelo SUS, porém mencionaram que o mesmo não era suficiente para o tratamento. Situação semelhante foi sido mencionada em outro estudo realizado no Brasil, em que pessoas em condição crônica em tratamento no domicílio, e suas famílias, arcam com gastos contínuos na compra de materiais para cuidados diários ${ }^{18}$.

Outros gastos do próprio bolso, mencionados pelos participantes, diz respeito à compra de medicamentos de uso contínuo. Além de ser a distribuição restrita e limitada, principalmente, com determinados medicamentos utilizados no tratamento de doenças crônicas que não se encontraram disponíveis nas UBS, ainda havia medicamentos que não estavam inclusos nos componentes da assistência farmacêutica. Este tema é complexo por várias razões, mas principalmente porque as pessoas adoecem e possuem outras doenças crônicas que também exigem o uso contínuo de medicamentos. Estes resultados coincidem com os de outros estudos que apontaram que os gastos com medicamentos ainda é o principal componente dos gastos com saúde nos usuários do sistema público brasileiro $^{12 ; 19}$, sobretudo entre os mais pobres, mulheres, idosos, e pessoas com doenças crônicas, comprometendo o orçamento familiar ${ }^{20}$.

Estudo que buscou descrever a prevalência e fatores associados ao acesso de usuários a medicamentos no SUS que tiveram prescrição no próprio sistema público, identificaram que apenas $45,3 \%$ desses usuários obtiveram todos os medicamentos gratuitamente ${ }^{19}$. Quando se considera os principais motivos para o não uso de medicamentos prescritos foram identificados não ter encontrado o medicamento na rede do SUS e, não ter dinheiro para comprá-los ${ }^{19,21}$. A disponibilização de medicamentos de forma contínua e em quantidade adequada às necessidades da população ainda é insuficiente e representa um desafio a ser superado, apontando para a necessidade de políticas que diminuam as desigualdades no acesso a medicamentos no país ${ }^{12,19}$.
Outra situação complexa e que vem se agravando no Brasil é a consulta com especialistas. Essa situação tem retardado o diagnóstico da DRC e levado às pessoas ao limite, quando são obrigadas a buscar um atendimento de emergência. Nesses momentos, elas e seus familiares se veem obrigadas a pagar pelas consultas e exames na medicina privada, de modo a agilizar o atendimento. Para algumas, uma das formas encontradas para melhorar o atendimento com especialistas e realizar os exames no momento da necessidade, era pagando um plano de saúde, uma situação que não era acessível a todos. Frente a este achado, estudos apontaram que as famílias com mais recursos econômicos pagam planos de saúde, uma vez que desejam ter um atendimento mais rápido; querem ter um atendimento diferenciado, como, por exemplo, nos serviços de hotelaria hospitalar, não cobertos pelo SUS; e porque acreditam que, em alguns casos, a assistência privada tem melhor qualidade que a pública ${ }^{3,7}$.

O comprometimento da capacidade do sistema público brasileiro de cumprir seus princípios leva uma parcela da população ao setor privado de cuidado em saúde em busca de resposta às suas demandas, elevando os gastos privados, o que pode ter impacto sobre as pessoas mais pobres ${ }^{8}$. Assim as pessoas com recursos econômicos que podem pagar por um plano de saúde terão como custear o próprio tratamento e cuidados, entretanto para aquelas com menor renda, mais pobres, podem não ter acesso aos cuidados e serviços de saúde, o que poderia gerar ainda mais gastos. Frente a isto, alguns estudos apontaram que pessoas com DRC de nível socioeconômico mais baixo têm menor probabilidade de receber tratamento ${ }^{11}$, que os tratamentos empobrecem as pessoas doentes sem proteção ${ }^{4}$, e que obstáculos no acesso à diálise acentuam as desigualdades sociais ${ }^{7}$.

Estudos também mencionam o uso do atendimento privado e público ${ }^{3,7}$, em que apenas uma parcela populacional pode ser coberta por planos privados e ainda usar os serviços públicos, beneficiando ainda mais os que podem pagar $^{22}$. Trata-se de um dos motivos da não concretização dos princípios da universalidade e gratuidade previstos pelo SUS no Brasil2 ${ }^{22}$. Essa situação tem se expandido cada vez mais e pode ser interpretada 
como uma forma de transferência das obrigações do Estado para as pessoas doentes e famílias, sobretudo as financeiras.

$\mathrm{Na}$ DP, por ser um tratamento domiciliar, a responsabilidade de garantir esse tratamento é repassada às pessoas doentes e suas famílias. Tal terapêutica pode ter um custo menor para o Estado, mas não necessariamente para as pessoas e famílias que enfrentam dificuldades, que em sua maioria abandonam o trabalho, e passam a viver com uma restrita aposentadoria mensal. Estudo apontou que pessoas com DRC em diálise são consideradas improdutivas por não conseguir manter vínculo formal com o trabalho devido ao regime do tratamento e condição clínica ${ }^{23}$. A mudança de vida no trabalho depois de iniciar a diálise é necessária e, além disto, faz com que as pessoas tenham que se adaptar para dar continuidade a vida laboral com a preocupação em recuperar e prover o sustento da família ${ }^{24}$.

O acesso universal e gratuito à saúde está descrito na Constituição Brasileira como direito fundamental de todos os cidadãos, e é dever do Estado em provê-lo e garanti-lo à população. De acordo, com este direito, as pessoas devem ter garantido o acesso aos especialistas, às tecnologias que envolvem a terapia dialítica, aos materiais, e aos medicamentos, e o que for necessário para a continuidade da assistência ${ }^{(5)}$. Entretanto, no País os gastos com saúde oneram importante parcela dos orçamentos das famílias e governamentais ${ }^{12,19}$.

Há uma intenção do Estado em aumentar o número de pessoas em DP frente a crescente incidência e prevalência da DRC, porém precisa ser repensado como ampliar essa modalidade de diálise, quando se percebe que as pessoas têm dificuldades e sofrem por não ter acesso a materiais básicos para realizar o tratamento. A falta dos materiais e equipamentos necessários à realização da diálise pode ter consequências quanto à efetividade da mesma, levando-os a complicações, como, por exemplo, a internações hospitalares por peritonites, o que gerará um custo ainda mais elevado para o Estado. Os gastos assumidos pelas pessoas com DRC em DP trazem um pesado ônus para pessoas de classes menos favorecidas. No entanto, há um esforço dessas pessoas em dar continuidade ao tratamento no domicílio, podendo levá-las ao prejuízo de outras necessidades presentes nas famílias.

\section{Conclusões}

Este estudo constatou que pessoas com DRC em CAPD no Brasil fazem gastos do seu próprio bolso para ter acesso e continuidade da atenção à saúde, particularmente no tratamento da diálise. No marco do SUS, constatamos que as pessoas com DRC têm que arcar com inúmeras despesas, uma vez que o sistema não dá conta de atender o conjunto de suas necessidades. As dificuldades vivenciadas pelos participantes, quando em busca do serviço público, os levam a pagarem do próprio bolso, como uma tentativa de dar continuidade ao tratamento, porém, não diminuindo o sofrimento causado por uma atenção que não cobre todos os gastos do tratamento renal.

Nossos achados mostram que o SUS brasileiro nem sempre garante um acesso gratuito ao tratamento desta população contribuindo para um repensar sobre a atenção a saúde oferecida. Trata-se de uma política sanitária que cobre parte das despesas com o tratamento de diálise. Portanto, há necessidade de políticas públicas que reduzam os gastos do próprio bolso, assim como as desigualdades no acesso à atenção a saúde (a medicamentos, a consultas médicas e exames no país) entre as pessoas com doença renal.

Recomenda-se, ainda, a realização de pesquisas acerca do tema com intuito de melhor compreender as dificuldades para acessar as TRS e os gastos com saúde a partir da trajetória destas pessoas pelo sistema de saúde.

\section{Referencias}

1. Liu F, Gao X, Inglese G, Chuengsaman P, Pecoits-Filho R, Yu A. A global overview of the impact of peritoneal dialysis first or favored policies: an opinion. Perit Dial Int.2015;35(4):406420 .

2. Sesso RC, Lopes AA, Thomé FS, Lugon JR, Martins CT. Inquérito Brasileiro de Diálise Crônica 2016. J. Bras. Nefrol. 2017;39(3):261-266.doi: http://dx.doi.org/10.5935/01012800.20170049 .

3. Zillmer JGV, Silva DMGV da. Tecendo reflexões sobre sofrimento social e doença renal crônica. Rev Enferm UFSM. 2016;2016;6(1):145-153. 
4. Mercado-Martínez FJ, Hernández-Ibarra E, Ascencio-Mera C, Díaz-Medina BA, Padilla-Altamira C, Kierans C. Viviendo con trasplante renal, sin protección social en salud: ¿Qué dicen los enfermos sobre las dificultades económicas que enfrentan y sus efectos? Cad. Saúde Pública.2014;30(10):2092-2100. doi http://dx.doi.org/10.1590/0102-311X00150713.

5. Ministério da Saúde (BR). Portaria GM/MS No 389, de 13 de março de 2014. Define os critérios para a organização da linha de cuidado da Pessoa com Doença Renal Crônica (DRC) e institui incentivo financeiro de custeio destinado ao cuidado ambulatorial pré-dialítico. Brasília: Ministério da Saúde; 2014. Diário Oficial da União [Internet], Brasília (DF). 14 mar. 2014 [cited 2018 Jul 9]. Seção 1:34. Available from: http: http://bvsms.saude.gov.br/bvs/saudelegis/ gm/2014/prt0389_13_03_2014.html

6. González Reyes MJ. Gasto de bolsillo en América Latina: Implicaciones políticas y económicas.2015;3(4).

7. Mercado-Martinez FJ, Silva DGV da, Souza SS, Zillmer JGV, Lopes SGR, Böell JE. Vivendo com insuficiência renal: obstáculos na terapia da hemodiálise na perspectiva das pessoas doentes e suas famílias. Physis.2015;25(1):59-74.doi: http://dx.doi.org/10.1590/S0103-73312015000100005.

8. Boing AC, Bertoldi AD, Barros AJD, Posenato LG, Peres KG. Desigualdade socioeconômica nos gastos catastróficos em saúde no Brasil. Rev Saude Publica.2014;48(4):632-641.doi: http://dx.doi.org/10.1590/S0034-8910.2014048005111

9. Gouveia DSS, Bignelli AT, Hokazono SR, Danucalov I, Siemens TA, Meyer F, et al. Análise do impacto econômico entre as modalidades de terapia renal substitutiva. J Bras Nefrol.2017;39:162-17.doi: http://dx.doi.org/10.5935/01012800.20170019 .

10. Silva SB, Caulliraux HM, Araújo CFS, Rocha E. Uma comparação dos custos do transplante renal em relação às diálises no Brasil. Cad Saúde Pública.2016;32:e00013515. doi: http:// dx.doi.org/10.1590/0102-311X00013515

11. Ganji S, Ephraim PL, Ameling JM, Purnell TS, LewisBoyer LL, Boulware LE. Concerns regarding the financial aspects of kidney transplantation: perspectives of pretransplant patients and their family members. Clin Transplant.2014;28:1121-1130.

12. Garcia LP, Sant’ana AC, Magalhães LCG, Aurea AP. Gastos com saúde das famílias brasileiras residentes em regiões metropolitanas: composição e evolução no período 19952009. Ciênc. saúde coletiva.2013;18(1):115-28.doi: http:// dx.doi.org/10.1590/S1413-81232013000100013.

13. Medina-Pestana JO, Galante NZ, Tedesco-Silva HJ, et al. O contexto do transplante renal no Brasil e sua disparidade geográfica. J Bras Nefrol.2011;4:472-484.doi: http://dx.doi. org/10.1590/S0101-28002011000400014.
14. Ferraz FHRP, Rodrigues CIS, Gatto GC, Sa NM. Diferenças e desigualdades no acesso a terapia renal substitutiva nos países do BRICS. Ciênc. saúde coletiva.2017;22(7): 2175-2185.doi: http://dx.doi.org/10.1590/1413-81232017227.00662017.

15. Pozzebon M. Conducting and evaluating critical interpretive research: Examining Criteria as a Key Component in Building a Research Tradition. IFIP - International Federation for Information Processing, 2004;143:275-292.

16. Hsieh HF, Shannon SE. Three approaches to qualitative content analysis. Qual Health Res 2005;15(9):1277-1288.

17. Ministério da Saúde (BR). Resolução no 466, de 12 de dezembro de 2012. Aprova as diretrizes e normas regulamentadoras de pesquisas envolvendo seres humanos. Diário Oficial da União [Internet], Brasília (DF). 13 jul. 2013 [cited 2013 jan 10]. Seção 1:59. Available from: http://bvsms. saude.gov.br/bvs/saudelegis/cns/2013/res0466_12_12_2012. html

18. Silva KL, Sena RR, Feuerwerker LCM, Silva PM, Martins ACS. Desafios da atenção domiciliar sob a perspectiva da redução de custos/racionalização de gastos. Rev Enferm UFPE.2014;8(6):1561-7.doi: https://doi.org/10.5205/19818963-v8i6a9846p1561-1567-2014

19. Boing AC, Bertoldi AD, Boing AF, Bastos JL, Peres KG. Acesso a medicamentos no setor público: análise de usuários do Sistema Único de Saúde no Brasil. Cad Saude Publica.2013;29(4):691-701.doi: http://dx.doi.org/10.1590/ S0102-311X2013000400007

20. Arsenijevic J, Pavlova M, Groot W. Measuring the catastrophic and impoverishing effect of household health care spending in Serbia. Social Science \& Medicine. 2013;78:17-25.

21. Paula EA, Costa MB, Colugnati FAB, Bastos RMR, Vanelli CP, Leite CCA et al. Potencialidades da atenção primária à saúde no cuidado à doença renal crônica. Rev. LatinoAm. Enfermagem. 2016;24:e2801. Doi: http://dx.doi. org/10.1590/1518-8345.1234.2801

22. Ocke-Reis CO, Marmor TR. The Brazilian National Health System: an unfulfilled promise. Int J Health Plann Mgmt.2010;25:318-329.doi: https://doi.org/10.1002/ hpm. 1014

23. Carneiro CT, Furtado AM, Meneghetti FK, Santos JAR, Bezerra MAR, Silva MLR, Rocha RC, Rocha SS. Vivências de adolescentes e jovens diagnosticados com doença renal crônica. Rev. Aten. Saúde.2018;16(57):24-29.

24. Cruz VFES, Tagliamento G, Wanderbroocke AC. A manutenção da vida laboral por doentes renais crônicos em tratamento de hemodiálise: uma análise dos significados do trabalho. Saúde Soc.2016;25(4):1050-1063.doi: http://dx.doi. org/10.1590/s0104-12902016155525.

\section{Como citar este artigo:}

Zillmer JGV, Silva DMGV. Gastos do próprio bolso das pessoas em diálise peritoneal: estudo qualitativo. Rev. Aten. Saúde. 2019; 17(61): 83-92. 